\title{
Recurrent acute pancreatitis due to pancreatic duct ascariasis in a young man
}

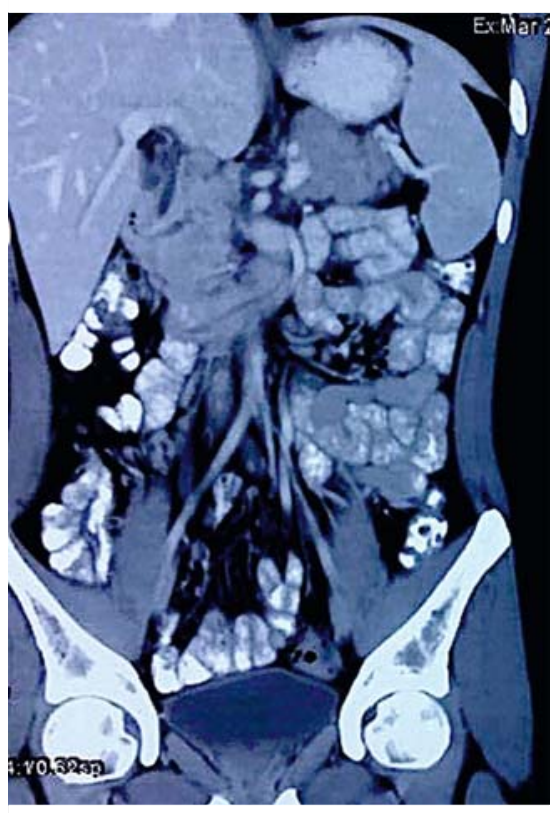

> Fig. 1 Contrast-enhanced computed tomography (CT) scan showing a linear hypodense structure in the second part of the duodenum.

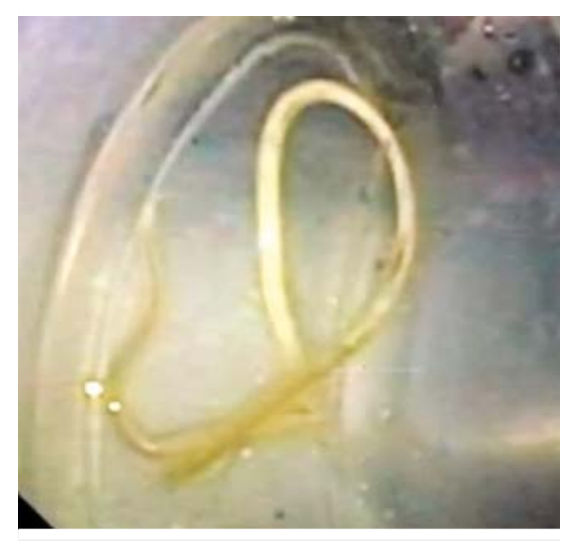

Fig. 4 The Ascaris worm after removal.

A 26-year-old man presented with abdominal pain and vomiting for 7 days. He had had similar complaints a few months previously. His laboratory evaluation showed a raised serum amylase $(878 \mathrm{IU} / \mathrm{dL})$ and a bulky pancreas on ultrasonography of the abdomen. Other etiological work-up for acute pancreatitis was normal. Contrast-enhanced computed tomography (CT) scanning re-

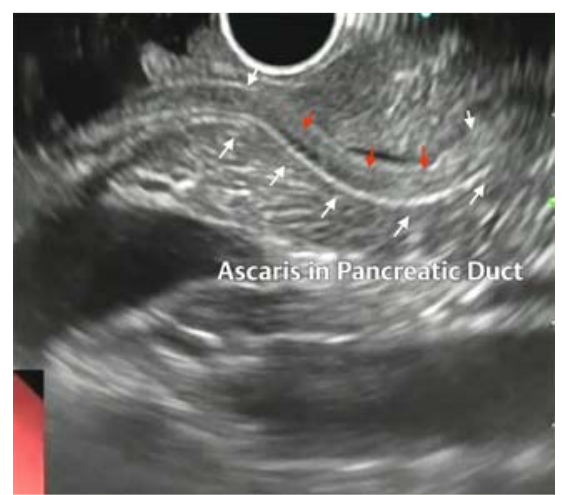

- Fig. 2 Endoscopic ultrasound showing the characteristic "strip sign" (two linear parallel echogenic lines without any acoustic shadow; white arrow) and central hypoechoic rim (inner tube sign; red arrow) typical of ascariasis in the pancre-

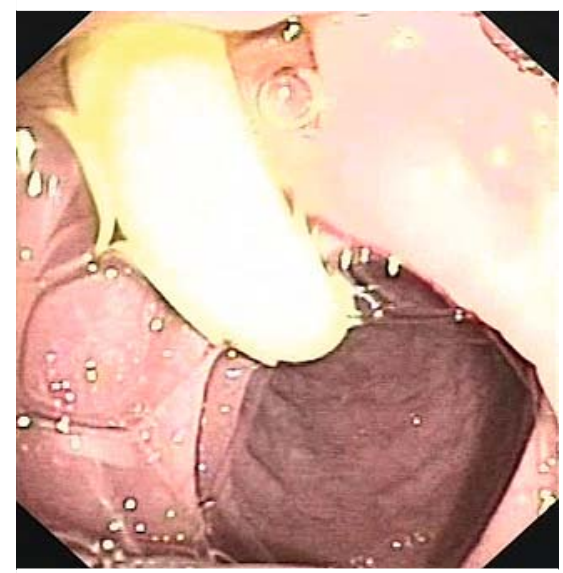

- Fig. 3 Endoscopic view showing the Ascaris worm popping out through the papilla. atic duct.
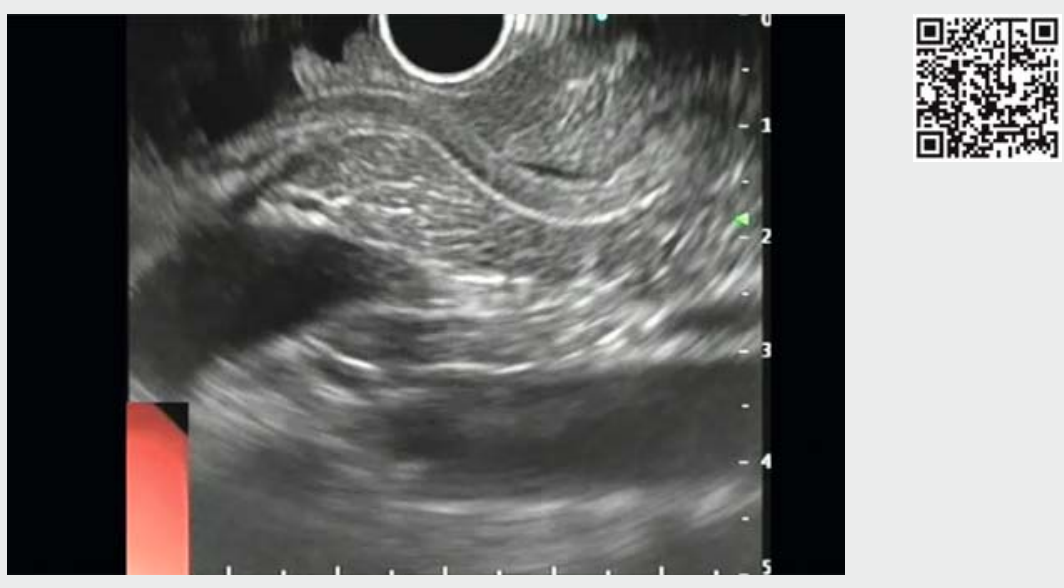

$\nabla$ Video 1 Video demonstrating the characteristic endoscopic ultrasound features of an Ascaris worm in the pancreatic duct, which is then removed endoscopically.

vealed a normal pancreas with a linear hypodense structure in the second part of the duodenum ( $\mathbf{F i g} \mathbf{1}$ ).

Endoscopic ultrasound (EUS) was performed to further evaluate the cause of this patient's recurrent pancreatitis. A linear echoendoscope (UCT-180; Olympus, Tokyo, Japan) was used for the pancreatobiliary examination. The gall bladder and common bile duct were normal and anechoic. Evaluation of the pancreas and pancreatic duct was initiated in the second part of the duodenum with the scope in the short position. At the level of the papilla, two linear parallel echogenic lines without any acoustic shadow (the "strip sign") and a thin central hypoechoic rim (the "inner tube sign") were seen within the pancreatic duct ( $\triangleright$ Fig. 2; $\triangleright$ Video 1). Tracing the lines 
further showed that the linear echogenic strip was occupying the entire duct and mimicking a pancreatic ductal stent.

After complete examination of the pancreas, the echoendoscope was positioned at the papilla and switched to endoscopy mode. A creamy white Ascaris worm could be seen popping partially out from the papilla ( $\mathbf{F i g . 3}$ ). The worm was grasped with rat-tooth forceps and removed along the scope ( $>$ Fig.4). Deworming was done for the patient and close family members and the patient has not suffered from any further episodes of abdominal pain as of his last follow-up.

Pancreatic ascariasis is a rare cause of acute pancreatitis even in endemic regions. The characteristic appearance on endosonography of the "strip sign" and "inner tube sign" is the key to diagnosis in these cases [1]. Endoscopic removal of the worm gives prompt relief of symptoms and subsequent deworming is essential to prevent recurrences.

Endoscopy_UCTN_Code_CCL_1AZ_2AF
Competing interests

None

The authors

Radhika Chavan, Mohan Ramchandani, Zaheer Nabi, Sundeep Lakhtakia, Jahangeer Basha, D. Nageshwar Reddy

Asian Institute of Gastroenterology, Hyderabad, India

\section{Corresponding author}

\section{Radhika Chavan, MD, DNB}

Asian Institute of Gastroenterology, Hyderabad, India

Fax: +91-40-23324255

drradhikachavan@gmail.com

\section{Reference}

[1] Sharma M, Somani P. EUS of pancreatic ascariasis. Arab J Gastroenterol 2018; 19 : $47-48$

\section{Bibliography}

DOI https://doi.org/10.1055/a-0651-0338

Published online: 10.8.2018

Endoscopy 2018; 50: E292-E293

(c) Georg Thieme Verlag KG

Stuttgart · New York

ISSN 0013-726X

\section{ENDOSCOPY E-VIDEOS}

https://eref.thieme.de/e-videos

回回 Endoscopy E-Videos is a free

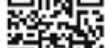
access online section, reportin 口i․ on interesting cases and new

techniques in gastroenterological endoscopy. All papers include a high quality video and all contributions are freely accessible online.

This section has its own submission website at https://mc.manuscriptcentral.com/e-videos 